\title{
Solvent-free synthesis of flavanones over aminopropyl-functionalized SBA-15
}

\author{
Xueguang Wang, Soofin Cheng * \\ Department of Chemistry, National Taiwan University, No. 1, Roosevelt Road Section 4, Taipei 106, Taiwan
}

Received 17 November 2005; received in revised form 15 February 2006; accepted 23 February 2006

Available online 3 March 2006

\begin{abstract}
Flavanone was synthesized through the Claisen-Schmidt condensation between benzaldehyde and acetophenone and subsequent intramolecular Michael addition over aminopropyl-functionalized SBA-15 materials. The catalysts with well-ordered hexagonally arranged mesopores were synthesized by one-pot co-condensation of tetraethoxysilane and aminopropyltriethoxysilane using amphiphilic block copolymer as the template under acidic condition. The results showed that the catalysts had good activities and very high selectivities to flavanone in solvent-free condition, while the use of organic solvents decreased the catalytic activities and flavanone selectivities. The influence of substituents in the aromatic rings of benzaldehyde and $2^{\prime}$-hydroxyacetophenone was also investigated under the solvent-free condition.
\end{abstract}

(C) 2006 Elsevier B.V. All rights reserved.

Keywords: Base catalysts; Mesoporous silica; Aminopropyl; Claisen-Schmidt condensation; Chalcone; Flavanone; Solvent-free

\section{Introduction}

The development of environmentally friendly solid catalysts for the synthesis of fine chemicals and pharmaceuticals is becoming an area of growing interest because the use of heterogeneous catalytic processes allows easier separation, recovery, and recycling of the catalysts from the reaction mixtures [1-3]. To maintain economic viability, a suitable heterogeneous system should also display activities and selectivities comparable or superior to the existing homogeneous route. Nevertheless, the number of available examples of successful transformation from homogeneous catalytic syntheses to heterogeneous ones is rather limited.

Flavonoids are polyphenolic compounds that are widely distributed in plants preserving the health of plants against infections and parasites. They have attracted increasing attention due to numerous pharmacological applications [4-10]. The synthesis of the flavonoids has been carried out through a variety of procedures, but the most common

\footnotetext{
${ }^{*}$ Corresponding author. Tel.: +886223638017; fax: +886223636359. E-mail address: chem1031@ntu.edu.tw (S. Cheng).
}

one is performed via the Claisen-Schmidt condensation and subsequent intramolecular Michael addition between substituted benzaldehydes and substituted 2'-hydroxyacetopheones in basic or acidic media under homogeneous conditions [11-13]. It is widely accepted that there is a need to develop clean and economical processes, where the use of noxious substances and the generation of wastes can be avoided.

In the past decade, various solid catalysts have been applied to flavanoid synthesis, such as magnesium oxide [14], alumina [15], barium hydroxides [16,17], hydrotalcites [18-20], and natural phosphates modified with $\mathrm{NaNO}_{3}$ or KF [21-23]. However, most of them require the use of expensive toxic solvents to facilitate the heat and mass transfer in the liquid phase reaction systems [14]. We have shown recently that amine-functionalized mesoporous SBA-15 silica was very effective for the synthesis of flavanone by Claisen-Schmidt condensation and subsequent isomerization reaction under solvent-free condition [24]. Herein a detailed study of the influence of solvents, amino group loadings, reaction conditions and substituting groups in the aromatic rings on the catalytic performance 
of amine-functionalized SBA-15 for the synthesis of flavanones was presented. Since elimination of organic solvents is a frequent goal in green chemistry, our catalyst represents a potentially valuable and clean route to prepare a large group of organic compounds useful for pharmaceuticals.

\section{Experimental}

\subsection{Sample preparation}

Surfactant $\mathrm{P} 123\left(\mathrm{EO}_{20} \mathrm{PO}_{70} \mathrm{EO}_{20}, M_{\mathrm{av}}=5800\right)$ was purchased from Aldrich and other chemicals of reagent grade were from Acros. All chemicals were used as received.

The aminopropyl-functionalized SBA-15 materials were prepared by a one-pot co-condensation method according to the literature [24]. Four grams of Pluronic 123 was dissolved in $125 \mathrm{~g}$ of $2.0 \mathrm{M} \mathrm{HCl}$ solution at room temperature. After adding TEOS, the resultant solution was equilibrated at $40{ }^{\circ} \mathrm{C}$ for $1 \mathrm{~h}$ to pre-hydrolyze TEOS, and then APTES was slowly added into the solution. The molar composition of the mixture was $(1-x)$ TEOS: $x$ APTES: $6.1 \mathrm{HCl}$ : 0.017 P123: $165 \mathrm{H}_{2} \mathrm{O}$, where $x$ varied from 0 to 0.20 , or the molar ratio of APTES/(TEOS + APTES) was 0-20\%. The resulting mixture was stirred at $40{ }^{\circ} \mathrm{C}$ for $20 \mathrm{~h}$ and then transferred into a polypropylene bottle and reacted at $90{ }^{\circ} \mathrm{C}$ under static condition for $24 \mathrm{~h}$. The solid product was recovered by filtration and dried at room temperature overnight. The template was removed from the as-synthesized material by refluxing in ethanol. Then the material was filtered, washed several times with water and ethanol and dried at $50^{\circ} \mathrm{C}$. The resultant samples are designated as $\mathrm{SBA}-\mathrm{NH}_{2}-x-\mathrm{P}$, where $\mathrm{P}$ denotes "prehydrolysis of TEOS" and $x$ is the molar percentage of the APTES/(TEO$\mathrm{S}+$ APTES). For comparison, a sample designated as SBA- $\mathrm{NH}_{2}-10$ was prepared by similar procedures except that TEOS and APTES were added to the acidic template solution at the same time without TEOS prehydrolysis. Another aminopropylated silica sample, denoted by $\mathrm{SiO}_{2}-\mathrm{NH}_{2}-10$, was synthesized without the addition of P123 template by the sol-gel process, where TEOS and APTES were added into an opening beaker with $125 \mathrm{~g}$ of $2.0 \mathrm{M} \mathrm{HCl}$ solution at $40{ }^{\circ} \mathrm{C}$ under stirring and the mixture was kept stirring at the same temperature until the water was dried out.

All the obtained dried solids were treated with $0.2 \mathrm{M}$ methanol solution of tetramethylammonium hydroxide (TMAOH) for $20 \mathrm{~min}$ to remove the residue $\mathrm{Cl}^{-}$ions ( $1.0 \mathrm{~g}$ of the gel per $50 \mathrm{~mL}$ of solution). Finally, the materials were filtered, washed several times with methanol and dried at $120^{\circ} \mathrm{C}$.

\subsection{Sample characterization}

X-ray powder diffraction (XRD) data were obtained on a Panalytical X'Pert Pro diffractometer using $\mathrm{Cu} \mathrm{K} \alpha$ radiation $(\lambda=1.5418 \AA)$ at $45 \mathrm{kV}$ and $40 \mathrm{~mA}$. $\mathrm{N}_{2}$ adsorption- desorption isotherms were carried out using a Micromeritics Tristar 3000 instrument at liquid nitrogen temperature. Before the measurements, the samples were degassed at $100{ }^{\circ} \mathrm{C}$ for $12 \mathrm{~h}$. The specific surface areas were evaluated using the Brunauer-Emmett-Teller (BET) method in the $P / P_{0}$ range of $0.05-0.3$. Pore size distribution curves were calculated using the desorption branch of the $\mathrm{N}_{2}$ adsorption-desorption isotherms and the Barrett-Joyner-Halenda (BJH) method. Elemental analyses (EA) were performed on a Heraeus CHN elemental analyzer.

\subsection{Catalytic reaction}

The liquid phase base-catalyzed reactions were carried out under $\mathrm{N}_{2}$ in a sealed flask immersed in a thermostat bath with a magnetic stirrer. In a typical experiment without the solvent, the reactants were mixed in the flask and heated to the set reaction temperature. Then, $0.15 \mathrm{~g}$ of the dried catalyst was rapidly added into the reactor. For the reactions in the presence of solvent, the mixture of the reactants in $5 \mathrm{ml}$ of solvent was heated to the reaction temperature before the dried catalyst was added into the reactor. The liquid products were separated from the reaction mixture at appropriate reaction intervals with a filtering syringe and diluted with chlorobenzene for analysis. The products were identified by GC-Mass spectrometry (HP5971 mass spectrometer connected with a $30 \times 0.25 \mathrm{~mm}$ RTX-50 capillary column) and analyzed by using a Chrompak CP 9000 gas chromatograph (GC) equipped with a $30 \mathrm{~m} \times 0.32 \mathrm{~mm}$ RTX-50 capillary column and an FID detector, where dodecane was used as the internal standard. The overall organic mass balance based on the starting reactants was more than $95 \%$.

\section{Results and discussion}

\subsection{Textural characteristics and chemical composition of the catalysts}

The TMAOH treated amino-functionalized materials with TEOS prehydrolysis showed one intense peak indexed to (100) reflection and two weak peaks of (110) and (200) reflections in their XRD patterns. The peak intensity weakens with the increase in the loading of amino groups in the samples from $5 \%$ to $20 \%$. On the other hand, the materials containing 10\% amino groups prepared without TEOS prehydrolysis $\left(\mathrm{SBA}-\mathrm{NH}_{2}-10\right)$ or without the addition of $\mathrm{P} 123$ template $\left(\mathrm{SiO}_{2}-\mathrm{NH}_{2}-10\right)$ were $\mathrm{X}$-ray amorphous. These results confirmed that the aminopropyl-functionalized materials synthesized with TEOS prehydrolysis had ordered pore structures and the TMAOH treatment had little influence on the ordering of mesoporous structure as reported previously [24].

The textural characteristics and chemical compositions of the modified materials after TMAOH treatment are summarized in Table 1. All the materials prepared with 
Table 1

Textural characteristics and chemical compositions of the amino-functionalized silica

\begin{tabular}{|c|c|c|c|c|c|c|}
\hline \multirow[t]{2}{*}{ Catalyst } & \multirow[t]{2}{*}{$D_{100}$ spacing $(\AA)$} & \multirow[t]{2}{*}{ Pore diameter $(\AA)$} & \multirow[t]{2}{*}{$S_{\mathrm{BET}}\left(\mathrm{m}^{2} / \mathrm{g}\right)$} & \multirow[t]{2}{*}{ Pore volume $\left(\mathrm{cm}^{3} / \mathrm{g}\right)$} & \multicolumn{2}{|c|}{$\mathrm{N}$ content $(\mathrm{mmol} / \mathrm{g})$} \\
\hline & & & & & Empirical & Theoretical \\
\hline Pure SBA-15 & 93 & 78 & 769 & 1.04 & 0 & 0 \\
\hline $\mathrm{SBA}-\mathrm{NH}_{2}-5-\mathrm{P}$ & 95 & 70 & 658 & 0.88 & 0.53 & 0.80 \\
\hline SBA-NH ${ }_{2}-10-\mathrm{P}$ & 92 & 63 & 565 & 0.72 & 1.23 & 1.54 \\
\hline 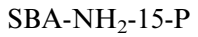 & 91 & 59 & 353 & 0.53 & 1.88 & 2.22 \\
\hline $\mathrm{SBA}-\mathrm{NH}_{2}-20-\mathrm{P}$ & 90 & 56 & 225 & 0.28 & 2.30 & 2.86 \\
\hline SBA-NH ${ }_{2}-10$ & - & - & 447 & 0.26 & 1.28 & 1.54 \\
\hline $\mathrm{SiO}_{2}-\mathrm{NH}_{2}-10$ & - & - & 542 & 0.28 & 1.57 & 1.54 \\
\hline
\end{tabular}

TEOS prehydrolysis exhibited the characteristic type IV nitrogen sorption isotherms and contained mesopores of narrow pore size distribution. Reasonably, the surface area and pore volume decreased with the amino content. In contrast, samples SBA- $\mathrm{NH}_{2}-10$ and $\mathrm{SiO}_{2}-\mathrm{NH}_{2}-10$ contained relatively low pore volumes.

\subsection{Synthesis of flavanones}

\subsubsection{Influence of solvent on the catalytic performance}

Flavonoids are commonly synthesized via the ClaisenSchmidt condensation between substituted benzaldehydes and substituted $2^{\prime}$-hydroxyacetopheones followed by the subsequent intramolecular Michel addition of the $2^{\prime}$ hydroxychalcone intermediates catalyzed by acids or bases $[11,14,18]$, as shown in Scheme 1. Blank experiment was carried out by mixing $2^{\prime}$-hydroxyacetophenone 1a and benzaldehyde 2a at $100-160^{\circ} \mathrm{C}$ and no reaction was observed. Pure siliceous SBA-15 treated with methanol solution of TMAOH was also tested for the catalytic condensation between $2^{\prime}$-hydroxyacetophenone and benzaldehyde at $140{ }^{\circ} \mathrm{C}$ for $8 \mathrm{~h}$. The reaction results showed that very low catalytic activities and conversions lower than $3 \%$ were observed with or without the solvents. In contrast, the amino-functionalized SBA-15 materials showed signif- icantly high conversions and flavanone selectivities, indicating that the amino groups instead of $\mathrm{Si}_{-} \mathrm{O}^{-}$groups were the catalytic active sites in this reaction.

Table 2 shows the solvent effect on the catalytic condensation of 2'-hydroxyacetophenone and benzaldehyde over SBA- $\mathrm{NH}_{2}-10-\mathrm{P}$ catalyst. Solvents were found to have great influence on the catalytic performance. However, there is no obvious correlation between the solvent polarity and the conversion or the flavanone selectivity. On the other hand, entry 6 in Table 2 shows that the catalyst has much higher conversion of 1a and selectivity to flavanone 4a under the solvent-free condition, indicating that the solvent molecules would hamper the conversion of the reactants. It is also noticed that the solvents containing benzene ring such as nitrobenzene, benzonitrile and trimethylbenzene gave relatively low flavanone selectivities, implying that these solvent molecules also interfere with the cyclization of $2^{\prime}$-hydroxychalcone $\mathbf{3 a}$ to form $\mathbf{4 a}$.

The conversions of the reactants were also influenced by the relative amounts of the reactants. When the $\mathbf{1 a} / \mathbf{2 a}$ molar ratio was reduced from 1:1 to 1:1.5 under solventfree condition, the conversion of 1a increased from $84 \%$ to $92 \%$ and the selectivity to $\mathbf{4 a}$ was retained around $70 \%$. The 1a/2a molar ratio of $1: 1.5$ was used for further studies hereafter. In all the reactions, no by-products other<smiles>[R]c1ccc(O)c(C(C)=O)c1</smiles>

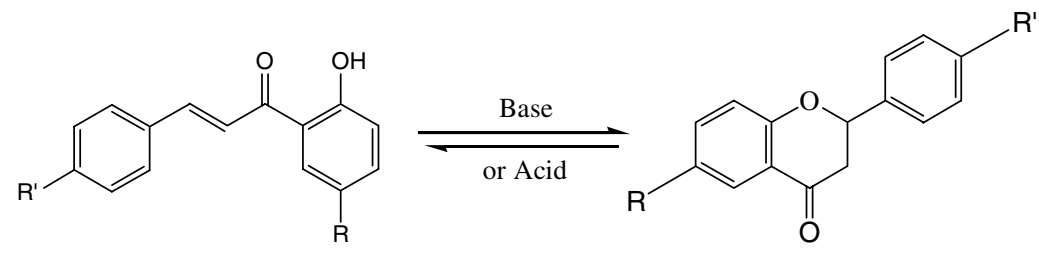

(ii) 
Table 2

The catalytic performance of SBA- $\mathrm{NH}_{2}-10-\mathrm{P}$ in the condensation of $2^{\prime}$-hydroxyacetophenone (1a) and benzaldehyde (2a) with and without solvents at $140{ }^{\circ} \mathrm{C}$ for $8 \mathrm{~h}^{\mathrm{a}}$

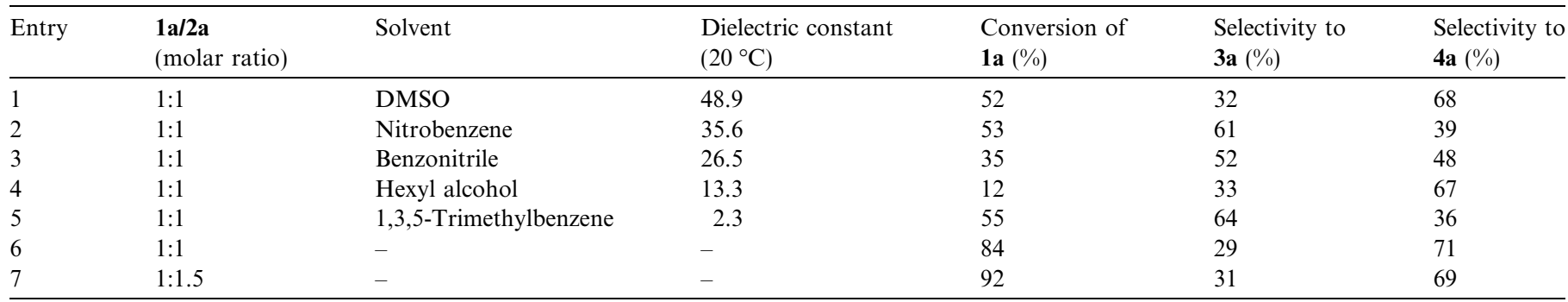

${ }^{a}$ Reaction conditions: $10 \mathrm{mmol} \mathrm{1a}$; 10 or $15 \mathrm{mmol} \mathrm{2a}$; $5 \mathrm{ml}$ solvent.

than chalcone and flavanone were detected by GC and GC-MS in the reaction products, indicating that neither Cannizzaro reaction of aldehyde nor condensation of ketone took place under the reaction conditions.

\subsubsection{Effect of reaction temperature and time on catalytic performance}

The effect of the reaction temperature on the catalytic activity and selectivity was examined between 110 and $160{ }^{\circ} \mathrm{C}$ in the absence of solvent over SBA- $\mathrm{NH}_{2}-10-\mathrm{P}$, and the results are illustrated in Fig. 1. It was found that the conversion of $2^{\prime}$-hydroxyacetophenone as well as the flavanone selectivity increased gradually with increasing reaction temperature from 110 to $140{ }^{\circ} \mathrm{C}$. As the temperature was further increased, the conversion and selectivity were almost unchanged and kept around $92 \%$ and $69 \%$, respectively. The leveling off of conversion is probably due to the blockage of catalytic centers by the high concentration of the products at this high conversion stage. On the other hand, the intramolecular isomerization of $2^{\prime}$-hydroxychalcone to form flavanone is a unimolecular reaction, it is expected that the entropy change of this isomerization is negligible. As a result, the selectivity to flavanone is independent of reaction temperature if the

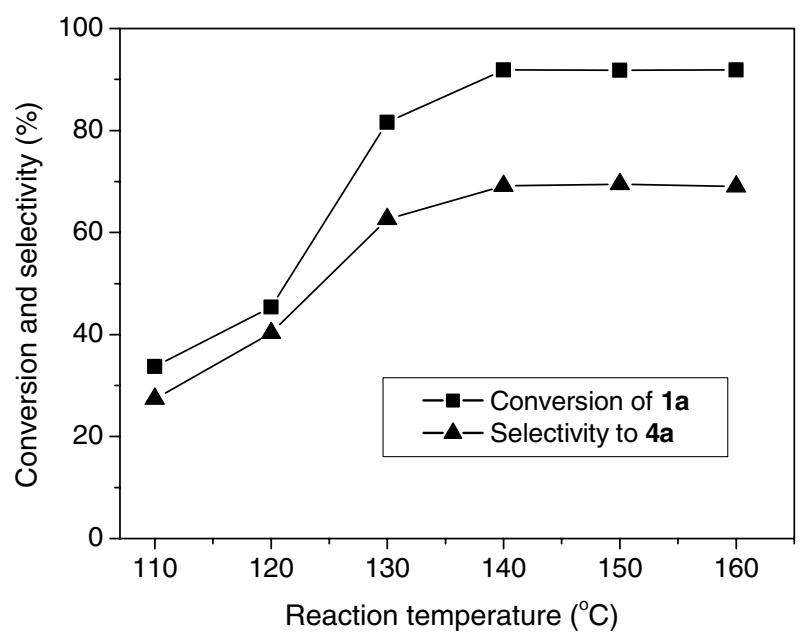

Fig. 1. Effect of reaction temperature on the catalytic performance. Reaction conditions: $10 \mathrm{mmol} \mathbf{1 a}+15 \mathrm{mmol} \mathbf{2 a}$; reaction time, $8 \mathrm{~h}$. final selectivity was determined by the thermodynamic equilibrium between 2 '-hydroxychalcone and flavanone.

The catalytic performance of sample SBA- $\mathrm{NH}_{2}-10-\mathrm{P}$ as a function of the reaction time in the condensation of benzaldehyde and $2^{\prime}$-hydroxyacetophenone was studied under solvent-free condition at $140{ }^{\circ} \mathrm{C}$ (Fig. 2). The catalytic activity was found to increase rapidly with the reaction time up to $8 \mathrm{~h}$ and then slow down. The selectivity to flavanone also increased gradually with time in $8 \mathrm{~h}$, and then it was kept around $69 \%$ as the reaction time was prolonged to

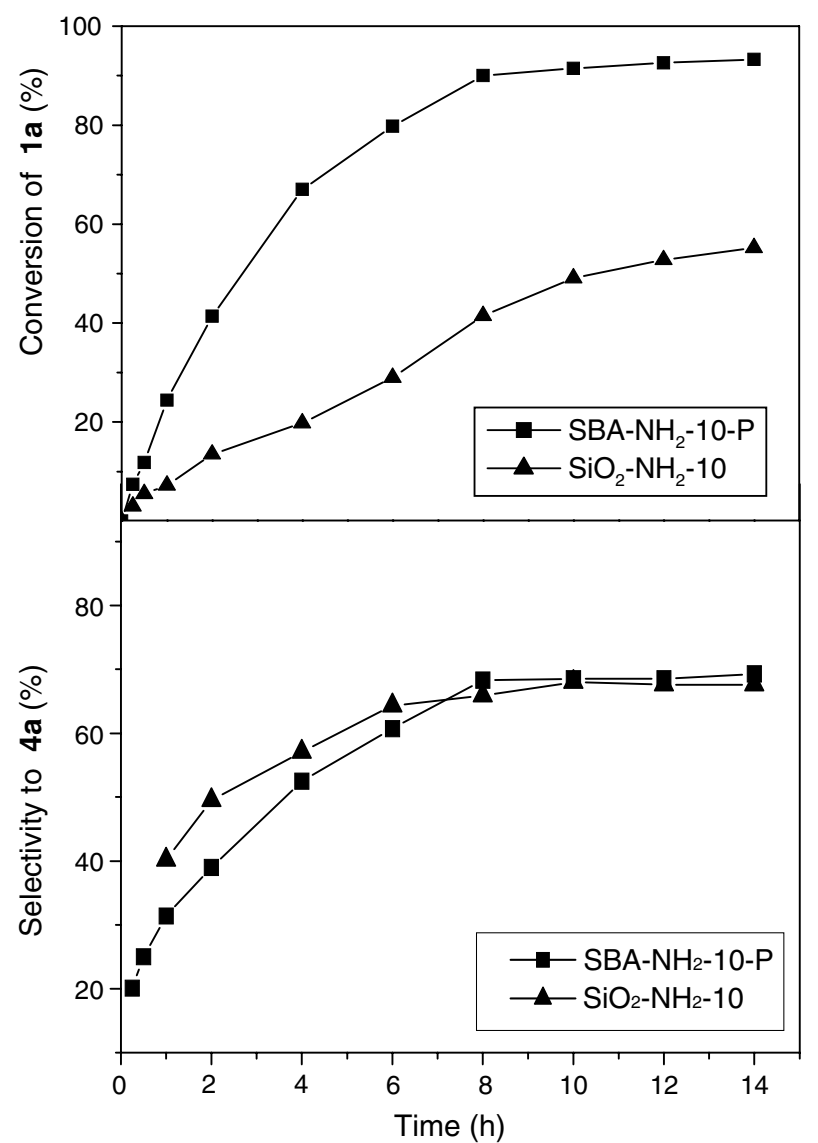

Fig. 2. The 1a conversion and selectivity to $\mathbf{4 a}$ as a function of reaction time over SBA- $\mathrm{NH}_{2}-10-\mathrm{P}$ and $\mathrm{SiO}_{2}-\mathrm{NH}_{2}-10$ in the absence of solvent. Reaction conditions: 1a, $10 \mathrm{mmol}$; $2 \mathbf{a}, 15 \mathrm{mmol}$; reaction temperature, $140{ }^{\circ} \mathrm{C}$. 
$14 \mathrm{~h}$. The final selectivity, supported by a separate experiment using flavanone as the reactant, was found to be determined by the thermodynamic equilibrium between $2^{\prime}$-hydroxychalcone and flavanone. When $0.15 \mathrm{~g}$ of the catalyst was heated with flavanone at $140^{\circ} \mathrm{C}$ for more than $8 \mathrm{~h}$, a portion of flavanone was converted to chalcone with the molar ratio of flavanone/(flavanone + chalcone) being around $69 \%$ and that was unchanged with prolonged reaction time.

\subsubsection{Influence of amino loading and porous structure}

The catalytic activities of ordered mesoporous SBA-15 catalysts prepared with TEOS prehydrolysis and containing different amounts of amino groups are displayed in Table 3. The conversion of $2^{\prime}$-hydroxyacetophenone reaches a maximum for the catalyst $\mathrm{SBA}-\mathrm{NH}_{2}-10-\mathrm{P}$, which contains $1.23 \mathrm{mmol} / \mathrm{g}$ amino groups. Thereafter, the conversion decreases gradually with the increase in the amino loadings. However, the selectivities to flavanone were all around $68 \%$ over this series of catalysts, indicating the attainment of thermodynamic equilibrium between $2^{\prime}$ hydroxychalcone and flavanone. The appearance of an optimal conversion for $10 \%$ amino loading is attributed to the decrease in surface area and pore volume of the materials with the increase in amino loading. On the other hand, the results of entries 2, 5 and 6 in Table 3 compare the performance of the three catalysts containing similar amino loadings around $10 \%$ but different crystallographic ordering. The amorphous samples $\mathrm{SBA}-\mathrm{NH}_{2}-10$ and $\mathrm{SiO}_{2}-\mathrm{NH}_{2}-10$ gave relatively lower conversions than SBA-NH $-10-\mathrm{P}$ of ordered pore structures. Especially, amorphous $\mathrm{SiO}_{2}-\mathrm{NH}_{2}-10$ which has the highest $\mathrm{N}$ content in the solids among these three catalysts, gave the lowest conversion, implying that a great portion of the amino groups are probably not accessible to the reactant molecules. Moreover, the ordered pore size and large pore volume on SBA-NH$-10-\mathrm{P}$ would facilitate the diffusion of the reactant and product molecules in the pore channels. The lower selectivities to flavanone over the amorphous catalysts are likely accounted for by assuming that the equilibrium between chalcone and flavanone was not reached yet. As the reaction time was prolonged to $10 \mathrm{~h}$, the selectivity to flavanone increased to $69 \%$, as shown in Fig. 2.

Table 3

Catalytic performance of the amino-functionalized silica materials with different amino loadings in the condensation of $2^{\prime}$-hydroxyacetophenone $(10 \mathrm{mmol})$ and benzaldehyde $(15 \mathrm{mmol})$ in the absence of solvent at $140{ }^{\circ} \mathrm{C}$ for $8 \mathrm{~h}$

\begin{tabular}{lllll}
\hline Entry & Catalyst & $\begin{array}{l}\text { Conversion } \\
\text { of } \mathbf{1 a}(\%)\end{array}$ & $\begin{array}{l}\text { Selectivity } \\
\text { to 3a }(\%)\end{array}$ & $\begin{array}{l}\text { Selectivity } \\
\text { to 4a }(\%)\end{array}$ \\
\hline 1 & SBA-NH $2-5-\mathrm{P}$ & 74 & 32 & 68 \\
2 & $\mathrm{SBA}-\mathrm{NH}_{2}-10-\mathrm{P}$ & 92 & 31 & 69 \\
3 & $\mathrm{SBA}_{2}-\mathrm{NH}_{2}-15-\mathrm{P}$ & 87 & 32 & 68 \\
4 & $\mathrm{SBA}_{2}-20-\mathrm{P}$ & 81 & 32 & 68 \\
5 & $\mathrm{SBA}_{2}-\mathrm{NH}_{2}-10$ & 61 & 38 & 62 \\
6 & $\mathrm{SiO}_{2}-\mathrm{NH}_{2}-10$ & 42 & 34 & 66 \\
7 & $\mathrm{Used}_{\mathrm{SBA}-\mathrm{NH}_{2}-10-\mathrm{P}}$ & 81 & 32 & 68 \\
\hline
\end{tabular}

In order to check the possible leaching of the active sites, the used catalyst SBA- $\mathrm{NH}_{2}-10-\mathrm{P}$ was treated with ethanol in a Soxhlet apparatus for $3 \mathrm{~h}$ and then dried at $100{ }^{\circ} \mathrm{C}$ overnight, and then it was reused as a catalyst for the condensation between 2'-hydroxyacetophenone and benzaldehyde under solvent-free condition. The result is shown in entry 7 in Table 3 . The catalyst gave $81 \%$ conversion of $2^{\prime}$-hydroxyacetophenone and $68 \%$ selectivity to flavanone, indicating that most of the active sites could be regenerated by a simple solvent treatment.

\subsubsection{Influence of substituting groups}

The catalytic reactions between various para-substituted benzaldehyde and 2'-hydroxyl-5'-substituted acetophenones were carried out in the absence of solvent over catalyst SBA- $\mathrm{NH}_{2}-10-\mathrm{P}$. The results are summarized in Table 4. All the reactions show relatively high conversions of acetophenones (1) and very high selectivities to flavanones (4). The substituting groups in the aromatic rings have great influence on the conversion and selectivity. The presence of the electron-withdrawing groups $(-\mathrm{Cl}$ and $-\mathrm{NO}_{2}$ ) at the para-position of benzaldehyde decreases the conversion but increases the flavanone selectivity, while the electron-donating groups $\left(-\mathrm{OCH}_{3}\right)$ on benzaldehyde favor the conversion of the reactants but decrease the selectivity to flavanones. These trends in conversion are opposite to those observed on other solid base or acid catalysts [18,22], implying that the Claisen-Schmidt condensation may have different reaction mechanism over the aminopropyl-functionalized silica [25].

In the previous studies on the adsorption of benzaldehyde on the aminopropyl xerogels, Sartori et al. [26,27] showed that the $\mathrm{C}=\mathrm{N}$ imine species were formed as the main surface component (Scheme 2) and a reaction mechanism for the nitroaldol condensation on the basis of imine formation was proposed. A similar reaction pathway is suggested here for the Claisen-Schmidt condensation over amine-functionalized mesoporous silica. The imine species are proposed to be one of the intermediates and the attack of imine by the anion of acetophenone produces the corresponding adducts. The first step of the imine formation is the attack by the nucleophilic amine on the carbonyl. A rapid proton transfer results in an unstable carbinolamine.

Table 4

Reactions between $2^{\prime}$-hydroxyacetophenone $(10 \mathrm{mmol})$ and benzaldehyde $(15 \mathrm{mmol})$ with various substituting groups in the absence of solvent over SBA- $\mathrm{NH}_{2}-10-\mathrm{P}$ at $140{ }^{\circ} \mathrm{C}$ for $8 \mathrm{~h}$

\begin{tabular}{llllll}
\hline Reaction & $\mathrm{R}$ & $\mathrm{R}^{\prime}$ & $\begin{array}{l}\text { Conversion } \\
\text { of } \mathbf{1}(\%)\end{array}$ & $\begin{array}{l}\text { Selectivity } \\
\text { to } \mathbf{3}(\%)\end{array}$ & $\begin{array}{l}\text { Selectivity } \\
\text { to } \mathbf{4}(\%)\end{array}$ \\
\hline$a$ & $\mathrm{H}$ & $\mathrm{H}$ & 92 & 31 & 69 \\
$b$ & $\mathrm{H}$ & $\mathrm{NO}_{2}$ & 66 & 14 & 86 \\
$c$ & $\mathrm{H}$ & $\mathrm{Cl}$ & 83 & 27 & 73 \\
$d$ & $\mathrm{H}$ & $\mathrm{CH}_{3} \mathrm{O}$ & 87 & 39 & 61 \\
$e$ & $\mathrm{CH}_{3} \mathrm{O}$ & $\mathrm{H}$ & 89 & 16 & 84 \\
$f$ & $\mathrm{Cl}$ & $\mathrm{H}$ & 92 & 25 & 75 \\
$g$ & $\mathrm{CH}_{3} \mathrm{O}$ & $\mathrm{CH}_{3} \mathrm{O}$ & 84 & 18 & 82 \\
\hline
\end{tabular}




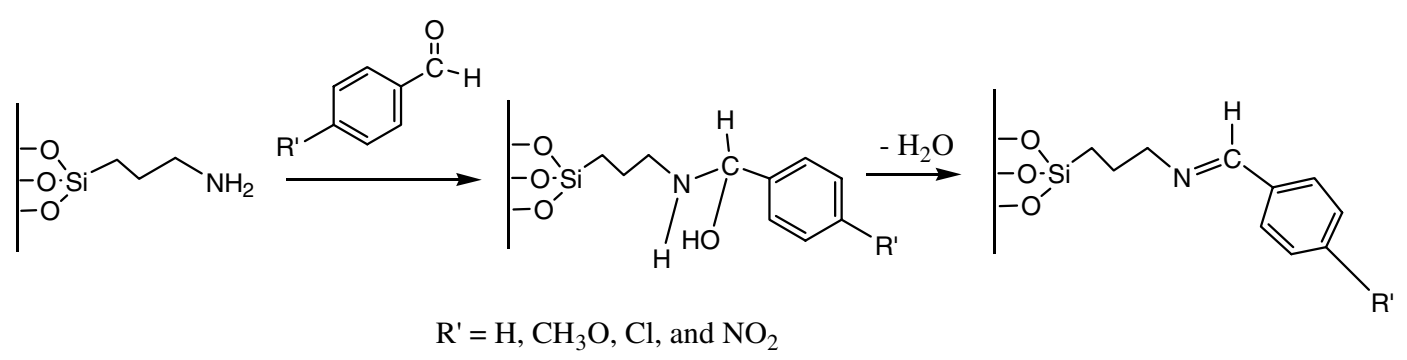

Scheme 2. Imine formation over amino-functionalized SBA-15.

The carbinolamine then reacts to form imine by the loss of water [28]. An electron-withdrawing group on benzaldehyde would favor the formation of carbinolamine intermediate but hinder the dehydration process and the formation of imine. As a result, the conversion of the reactants decreases. On the other hand, the influence of the substituents at the meta position of acetophenone on the conversion seems to be less significant. Both the electrondonating and -withdrawing groups in the aromatic rings of acetophenone can enhance the selectivity to flavanones (cf. Reactions a, e and $\mathrm{f}$ in Table 4). The results are probably due to the difference in the thermodynamic distributions of products $\mathbf{3}$ and $\mathbf{4}$ among the compounds containing different substituents. The geometric effect which restricts the diffusion and adsorption of reactants was proposed for the decrease in catalytic activities over other solid catalysts like barium hydroxide, zeolites and hydrotalcites when large substituting groups such as $\mathrm{NO}_{2}^{-}, \mathrm{Cl}^{-}$and $\mathrm{CH}_{3} \mathrm{O}^{-}$was present on the reactants [1620]. However, this effect seems to be negligible in our system, probably due to that the large mesoporous structure provides a relatively open space for diffusion.

\section{Conclusions}

Aminopropyl-functionalized SBA-15 of ordered hexagonally arranged mesoporous structure was an efficient base catalyst for the synthesis of flavanones via the Claisen-Schmidt condensation between 4-substituted benzaldehydes and 2'-hydroxyacetopheones and the subsequent isomerization of the $2^{\prime}$-hydroxychalcone intermediates in the absence of solvent. The use of solvents markedly decreased both the catalytic activity and the selectivity to flavanone. The ordered pore size and large pore volume of the amino-functionalized SBA-15 facilitate the diffusion of the reactant and product molecules in the pore channels. The optimal conversion was obtained for the functionalized SBA-15 synthesized with 10\% APTES/ (TEOS + APTES) molar ratio in the initial mixture. The catalytic activity decreased with higher amino loading on SBA-15 probably due to the decrease in surface area and pore volume. The substituents in the aromatic rings of the benzaldehyde have great effect on the catalytic performance in the Claisen-Schmidt condensation under solvent-free condition. The presence of the electron-withdrawing groups at the para-position of benzaldehyde decreased the conversion but increased the flavanone selectivity, while electron-donating groups on benzaldehyde favored the conversion but decreased the selectivity to flavanones. The results were explained by the formation of imines as the intermediates.

\section{Acknowledgement}

This project was supported by the National Science Council, Taiwan.

\section{References}

[1] R.A. Sheldon, R.S. Downing, Appl. Catal. A 189 (1999) 163.

[2] M. Besson, M.C. Bonnet, P. Gallezot, I. Tkatchenko, A. Tuel, Catal. Today 51 (1999) 547.

[3] Y. Kubota, Y. Nishizaki, H. Ikeya, M. Saeki, T. Hida, S. Kawazu, M. Yoshida, H. Fujii, Y. Sugi, Micropor. Mesopor. Mater. 70 (2004) 135.

[4] R. Li, G.L. Kenyon, F.E. Cohen, X. Chen, B. Gong, J.N. Dominguez, E. Davison, G. Kurzban, R.E. Miller, E.O. Nuzman, J. Med. Chem. 38 (1995) 5031.

[5] A.T. Dinkova-Kostova, C. Abeygunawardana, P. Talaley, J. Med. Chem. 41 (1998) 5278.

[6] J.F. Ballesteros, M.J. Sanz, A. Ubeda, M.A. Miranda, S. Iborra, M. Paya, M.J. Alcaraz, J. Med. Chem. 38 (1995) 2794.

[7] J.R. Dimmock, N.M. Kandepu, M. Hetherington, J.W. Quail, U. Pugazhenthi, A.M. Sudom, M. Chamankhah, P. Rose, E. Pass, T.M. Alle, S. Halleran, J. Szydlowski, B. Mutus, M. Tannous, E.K. Manavathu, T.G. Myers, E.D. Clercq, J. Balzani, J. Med. Chem. 41 (1998) 1014.

[8] M.D. Ankhiwala, J. Indian Chem. Soc. 67 (1990) 913.

[9] A. Mantas, E. Deretey, F.H. Ferretti, M.R. Estrada, I.G. Csizmadia, THEOCHEM 504 (2000) 171.

[10] R.T. Blickenstaff, W.R. Hanson, S. Reddy, R. Witt, Bioorg. Med. Chem. 3 (1995) 917.

[11] D.N. Dahr, The Chemistry of Chalcones and Related Compounds, Wiley, New York, 1981.

[12] J.B. Harbone, T.J. Mabry, H. Mabry, The Flavonoids, Academic Press, New York, 1976.

[13] J.B. Harbone, T.J. Mabry, The Flavonoids: Advances in Research, Chapman \& Hall, New York, 1982.

[14] M.T. Drexler, M.D. Amiridis, J. Catal. 214 (2003) 136.

[15] R.S. Varma, G.W. Kabalka, L.T. Evans, R.M. Pagni, Synth. Commun. 15 (1985) 279.

[16] A. Aguilera, A.R. Alcantara, J.M. Marinas, J.V. Sinisterra, Can. J. Chem. 65 (1987) 1165.

[17] A. Fuentes, J.M. Marinas, J.V. Sinisterra, Tetrahedron Lett. 28 (1987) 4541.

[18] M.J. Climent, A. Corma, S. Iborra, J. Primo, J. Catal. 151 (1995) 60.

[19] A. Guida, M.H. Lhouty, D. Tichit, F. Figueras, P. Geneste, Appl. Catal. A 164 (1997) 251.

[20] M.J. Climent, A. Corma, S. Iborra, A. Velty, J. Catal. 221 (2004) 474. 
[21] S. Sebti, A. Solhy, R. Tahir, S. Abdelatif, S. Boulaajaj, J.A. Mayoral, J.I. Garcia, J.M. Fraile, A. Kossir, H. Oumimoun, J. Catal. 213 (2003) 1.

[22] D.J. Macquarrie, R. Nazih, S. Sebti, Green Chem. 4 (2002) 56.

[23] S. Sebti, A. Saber, A. Rhihil, R. Nazih, R. Tahir, Appl. Catal. A 206 (2001) 217.

[24] X.G Wang, K.S.K. Lin, J.C.C. Chan, S. Cheng, J. Phys. Chem. B 109 (2005) 1763.
[25] X.G Wang, Y.-H. Tseng, J.C.C. Chan, S. Cheng, J. Catal. 233 (2005) 266.

[26] G. Sartori, F. Bigi, R. Maggi, R. Sartorio, D.J. Macquarrie, M. Lenarda, L. Storaro, S. Coluccia, G. Martra, J. Catal. 222 (2004) 410.

[27] F. Bigi, S. Carloni, R. Maggi, A. Mazzacani, G. Sartori, Stud. Surf. Sci. Catal. $130(2000) 3501$.

[28] L.G. Wade Jr., Organic Chemistry, Prentice-Hall International, Inc., NJ, 1987. 